\title{
Altas tecnologías, conflictos armados y seguridad humana
}

\section{High-Technologies, Armed Conflicts and Human Security}

\author{
Elena del Mar García Rico ${ }^{1}$ \\ Universidad de Málaga (España)
}

Recibido: 01-02-16

Aprobado: 25-04-16

\section{Resumen}

El examen de las amenazas para la seguridad y el bienestar de las personas inherentes al concepto de seguridad humana exige ocuparse también de las consecuencias que la utilización de las altas tecnologías puedan ocasionar en relación con los conflictos armados actuales.

De ahí que en este trabajo abordemos los cambios relevantes en la naturaleza y características de los nuevos conflictos armados provocados por la celeridad y amplitud en el empleo de altas tecnologías y su desigual distribución entre los beligerantes, tal y como muestran las llamadas guerras de coste cero, de cuarta generación o asimétricas, e incluso las híbridas. Asimismo, el desarrollo reciente de las capacidades militares cibernéticas, de los sistemas de armas autónomos y de los vehículos aéreos no tripulados plantea nuevos retos al Derecho Internacional Humanitario, aspectos contemplados en este estudio.

Palabras-clave: Altas tecnologías, ciberguerras, derecho internacional humanitario, drones, guerras asimétricas, guerras de coste cero.

\footnotetext{
${ }^{1}$ (egarcia@uma.es) Profesora Titular de Derecho Internacional Público y Relaciones Internacionales Universidad de Málaga. El presente estudio se enmarca dentro de la Red de Excelencia sobre "Los actuales desafíos del Derecho Internacional", del Plan Estatal de Investigación Científica y Técnica y de Innovación 2013-2016 (DER15-69273-RED).
} 


\begin{abstract}
Today, a global analysis of the concept of "Human security" requires a necessary approach to the consequences of high-technologies and their relationship with new categories of armed conflicts.

The speed and breadth in the use of high technology in recent years, next to its unequal distribution between the belligerents, have led to significant changes in the nature and characteristics of the new armed conflicts (as shown by zero casualty warfare, asymmetric and hybrid warfare or cyber warfare). Revolutionary advances in emerging technologies of warfare, notably those relying on cyberspace warfare capabilities, autonomous weapon systems and drones, give rise to new challenges in the field of International Humanitarian Law.
\end{abstract}

Key-words: High-Technologies, Cyber Warfare, International Humanitarian Law, drones, Asymmetrical Warfare, Zero casualty warfare.

\title{
1. Introducción
}

La inclusión del concepto de "seguridad humana" en el Informe Anual sobre Desarrollo Humano elaborado por el Programa de Naciones Unidas para el Desarrollo (PNUD) en $1994^{2}$ puso de manifiesto un nuevo enfoque del concepto de seguridad centrada en el ser humano y constituye la expresión más acabada de los esfuerzos desarrollados en el seno de la sociedad internacional por promover una comprensión más amplia y multidimensional de la seguridad.

Desde entonces hemos asistido por parte de Naciones Unidas a la creación y consolidación de un marco normativo dinámico y práctico que permita hacer frente a las amenazas de carácter intersectorial y generalizado a las que se enfrentan no sólo los gobiernos, sino también las personas. En el seno de esta organización internacional, en efecto, se ha procurado ofrecer un nuevo enfoque que combine los programas de paz y seguridad, desarrollo y derechos humanos desde una perspectiva integrada que "ayuda a los Estados Miembros a determinar y superar las dificultades generalizadas e intersectoriales que afectan a la supervivencia, los medios de subsistencia y la dignidad de sus ciudadanos"3.

La adopción por la Asamblea General de N.U. de la Resolución 66/290 tras el debate oficial auspiciado por su Presidente en 2012, vino a clarificar los

\footnotetext{
${ }^{2}$ Informe sobre Desarrollo Humano1994. Programa de Naciones Unidas para el Desarrollo, disponible en http://hdr.undp.org/en/reports/global/hdr1994/chapters/spanish/ (consultado en enero de 2016, al igual que el resto de los enlaces).

${ }^{3}$ Resolución 66/290 de la Asamblea General de N.U., de 25 de octubre de 2012.
} 
contornos siempre polémicos de la noción de seguridad humana arrojando luz sobre su contenido y alcance. En este sentido, resulta interesante destacar la afirmación que se contiene en la misma, relativa a que el concepto de seguridad humana es distinto de la responsabilidad de proteger y no entraña la amenaza o el uso de la fuerza ni medidas coercitivas ni sustituye a la seguridad del Estado.

Sin embargo, ello no significa en nuestra opinión que se deba sustraer necesariamente del ámbito de estudio acerca de la seguridad humana cualquier aspecto relacionado con la paz y seguridad internacional y, por consiguiente, con el uso de la fuerza en las relaciones internacionales. De hecho, como apuntaba la Asamblea General en la mencionada Resolución, "la seguridad humana reconoce la interrelación de la paz, el desarrollo y los derechos humanos"4.

Situados pues en esta perspectiva, hemos de convenir que si bien tradicionalmente el término seguridad se refería únicamente a los Estados y su objetivo se centraba en la ausencia de amenazas de carácter militar para los mismos, en la actualidad la seguridad ya no está marcada únicamente por su componente defensivo, ni son los medios militares las únicas herramientas para satisfacer sus intereses. Por el contrario, cualquier examen de la seguridad y sus factores de riesgo o amenaza, cuya ausencia constituye uno de los pilares de la seguridad humana ${ }^{5}$, ha de tomar en consideración sus aspectos políticos, militares, sociales, económicos, humanitarios y medioambientales, que conforman una visión más compleja y heterogénea de seguridad.

Ahora bien, dado que el análisis de las amenazas a la seguridad humana requiere una evaluación amplia, centrada en las personas, específica para cada contexto y orientada a la prevención, resulta necesario centrar la atención en las amenazas existentes y emergentes para la seguridad y el bienestar de las personas y las comunidades, incluidas aquellas que se derivan de las consecuencias que la utilización de altas tecnologías puedan ocasionar en relación con los conflictos armados que se suceden y multiplican en la sociedad internacional contemporánea.

De ahí que en el marco del amplio estudio sobre la seguridad humana que constituye el monográfico en el que se inserta nuestra contribución, consideremos de interés abordar algunos de los aspectos relacionados con los cambios que los avances tecnológicos han propiciado tanto en la naturaleza y

\footnotetext{
${ }^{4}$ Ibídem, apto. 3, c). La cursiva es nuestra. No en vano, como señala algún autor, "las definiciones de paz, de seguridad y de desarrollo empiezan a mostrar rasgos análogos...y el actor referente al que debe proporcionarse o asegurar paz, seguridad y desarrollo pasan a ser las personas": vid. Rafael Grasa, Cincuenta años de evolución de la investigación para la paz, Barcelona, Colección Recerca per la Pau. Oficina de Promoció de la Pau i dels Drets Humans. Generalidad de Cataluña, 2010. pg. 73.

5 No en vano, como apunta Margarita Robles Carrillo, "los pilares esenciales de la seguridad humana son la ausencia de amenazas - peligros vitales- la ausencia de necesidades -vulnerabilidades sociales-y la ausencia, en la medida de lo posible, de desastres naturales con consecuencias sociales devastadoras": vid. Margarita Robles Carrillo, La integración de la perspectiva de género en el análisis de los conflictos armados y la seguridad, "Cuadernos de Estrategia", 157 (2012), p. 66.
} 
caracteres de los conflictos armados del siglo XXI como los retos humanitarios y jurídicos que suscitan los nuevos métodos y medios de guerra ligados a las altas tecnologías.

\section{Las altas tecnologías y los conflictos armados: novedades y desafíos}

Los avances tecnológicos en el ámbito militar ocupan un lugar destacado en el surgimiento de nuevos medios y métodos de guerra que confieren rasgos particulares a los conflictos armados de la nueva centuria y constituyen uno de sus principales elementos de cambio.

Podría aducirse, no sin cierta fundamentación, que estos avances constituyen un factor tradicional de los conflictos armados: desde el arco y la flecha a los misiles intercontinentales, desde las trincheras a los satélites espaciales, y así en una lista interminable al igual que terrorífica, la historia de la humanidad está marcada por la aparición de nuevos tipos de armas y métodos de combate y su intento de regulación y limitación a través de normas apropiadas.

No obstante, lo que convierte este elemento habitual de los conflictos armados en algo auténticamente novedoso es, en primer lugar, la celeridad y amplitud de los avances tecnológicos militares más recientes, que ha merecido el calificativo de auténtica "revolución" tanto por parte de la doctrina ${ }^{6}$ como de los estrategas y autoridades militares ${ }^{7}$, que acuñaron ya en la década de los años ochenta del siglo pasado la expresión "Revolution in Military Affairs" (más conocida por las siglas RMA en inglés), con la que se "intenta describir cómo las nuevas tecnologías de la información aplicadas al mando y control de las unidades militares en operaciones están transformando el modo de entender la guerra".

${ }^{6}$ Tal y como la califica en la doctrina Michael N. Schmitt, The Principle of Discrimination in 21st Century Warfare, "Yale Human Rights and Development Law Journal", 143 (1999), pp. 143-182, p. 143. Por su parte, Douglas Kellner, habla de "revolution" in terms of the deployment of precision targeting at a distance and use of computers, also noting conservative military resistance to calls for dramatic transformation of the military: vid. Douglas Kellner, The Politics and Cost of Postmodern War in the Age of Bush II, disponible en https://pages.gseis.ucla.edu/faculty/kellner/papers/POMOwar. htm. Para una amplia visión sobre la aportación doctrinal en esta materia, vid. Javier Jordán y Josep Baqués, Guerra de Drones. Política, tecnología y cambio social en los nuevos conflictos, Madrid, Biblioteca Nueva, 2014, pp. 49-52.

7 Este nuevo paradigma militar ha estado liderado, en la práctica, desde sus inicios por las autoridades militares y políticas de Estados Unidos: vid. Frank Hoffman, Complex-irregular warfare: The next Revolution in Military Affairs, "Orbis”, 50 (2006), pp. 395-411. En nuestro país, vid. Guillem Colom, Entre Ares y Atenea: el debate sobre la Revolución en los Asuntos Militares, Madrid, Instituto Universitario General Gutiérrez Mellado, 2008.

${ }^{8}$ Federico Aznar Fernández-Montesinos y Andrés González Martí, Las generaciones de guerra. Guerras de segunda y tercera generación (II), "Boletín Electrónico del Instituto Español de Estudios Estratégicos”, Documento de Análisis 59/2015, p. 18. 
Esta "revolución en asuntos militares", sostenida sobre tres pilares tecnológicos: sensores, sistemas de comunicación y armamento ${ }^{9}$, venía a poner de manifiesto la transformación de los conflictos armados con la incorporación de las tecnologías de la información a éstos y el desarrollo de formas más descentralizadas de organización militar en el seno de una sociedad permanentemente interconectada.

No en vano, como se ha apuntado, "una RMA se define como un profundo cambio en la forma de combatir que, motivada por la integración de nuevas tecnologías, doctrinas, formas de organización de la fuerza y conceptos que guían su empleo en operaciones, convierte en irrelevante u obsoleto el estilo militar anterior"10.

Con estos nuevos medios se adquiere una visión general del teatro de operaciones bélicas gracias a la reducción de la incertidumbre que posibilita la digitalización de la realidad". Además, "la tecnología permite seccionar al enemigo siguiendo las líneas de fractura de las sociedades lo que posibilita el hacerlo con menos daños materiales y bajos niveles de resistencia, convirtiendo así en inoperantes los medios del rival con golpes incisivos dirigidos contra sus infraestructuras y sus sistemas de mando y control" ${ }^{2}$. De este modo se simplifica enormemente las estructuras de mando y la transferencia del control directo de las operaciones al poder político y se garantiza operaciones limpias e incluso "amables"13 que se presentan como especialmente adecuadas en el contexto actual de crisis económica y el consiguiente recorte en los gastos militares ${ }^{14}$.

En la misma línea cabría mencionar la doctrina militar estadounidense formulada por la Junta de Jefes de su Estado Mayor en 1996 en torno al concepto de "precision engagement"15 o "combate de precisión". Ésta supone dotar de un nuevo significado al término "precisión", que ya no va referido exclusivamente

\footnotetext{
${ }^{9}$ Así, "Los sensores proporcionan un cuadro completo y digitalizado del campo de batalla, esta información - una auténtica avalancha de datos- es transmitida por avanzados sistemas de telecomunicaciones y es volcada en sistemas adecuados para su tratamiento. Desde los Cuarteles Generales y en función del teatro y de los objetivos de la guerra se designan los blancos (targeting) y se les asignan modernos sistemas de armas inteligentes", ibídem, p. 18.

${ }_{10}$ Guillem Colom Piella, Cambio y continuidad en el pensamiento estratégico estadounidense desde el final de la Guerra Fría, "Revista de Ciencia Política", 33 (2013), pp. 675-692.

${ }^{11}$ Andrés González Martín y otros, Evolución del pensamiento estratégico, Documento de Trabajo del Departamento de Estrategia. X Curso de Estado Mayor de las Fuerzas Armadas, Madrid, Ministerio de Defensa, 2008.

${ }^{12}$ Federico Aznar Fernández-Montesinos y Andrés González Martí, Las generaciones de guerra. Guerras de segunda y tercera generación (II), op. cit., p. 19.

${ }^{13}$ Charles-Philippe David, La guerra y la paz, Barcelona, Icaria, 2008, p. 222.

${ }^{14}$ En opinión, que compartimos, de Guillem Colom, El auge de los conflictos hibridos,"Boletín Electrónico del Instituto Español de Estudios Estratégicos”, Documento de Opinión 120/2014, p. 5.

${ }^{15}$ Una noción que "will consist of a system of systems that enables military forces to locate the objective or target, provide responsive command and control, generate the desired effect, asses the level of success, and retain the flexibility to re-engage with precision when required": vid. U.S. Joint Chiefs of Staff. Joint Vision 2010 (1996), pp. 6.
} 
a la capacidad para llevar a cabo un ataque contra un blanco determinado, sino a la conjunción de una doble capacidad: la de tener el control y dominio de la información necesaria para llevar a cabo el ataque (relacionado con la vigilancia y reconocimiento de la situación sobre el terreno) y, en segundo término, la de aplicar el grado justo y necesario de fuerza para lograr el objetivo deseado.

Por consiguiente, las guerras de precisión requieren no sólo poseer el tipo de armamento más eficaz, sino también una cadena de mando robusta que controle y reciba la información necesaria para adoptar una decisión que los subordinados deberán ejecutar a través del tipo de armamento más adecuado para alcanzar su objetivo y respetar las normas que establece en esta materia el ius in bello o Derecho Internacional Humanitario ${ }^{16}$ (en adelante, DIH).

Como podemos observar de lo expuesto, el nivel tecnológico de los beligerantes resulta un factor determinante hasta el punto de forzar una diferencia básica entre, por un lado, los contendientes que tienen a su disposición los más sofisticados y eficientes medios de combate y, por otro, quienes no los tienen ${ }^{17}$.

Se configura así el segundo de los aspectos que confiere a los avances tecnológicos inherentes a la propia evolución de los conflictos armados un carácter novedoso: la desigual distribución de los mismos entre los Estados que conforman la sociedad internacional actual ${ }^{18}$.

En este sentido, resulta evidente que se ha ido abriendo y consolidando una auténtica brecha entre los Estados con una alta tecnología militar y aquellos que no sólo no la poseen sino que, simplemente, no tienen posibilidad de acceso a la misma, rompiendo de este modo el principio básico de igualdad de armas entre los contendientes e imponiendo la distinción, en un escenario global que no conoce de fronteras estatales, entre los denominados Estados "high-tech" y "low-tech", respectivamente ${ }^{19}$.

Esta desigualdad manifiesta entre los contendientes, auspiciada por una economía basada en los conocimientos más que en las materias primas o el desarrollo industrial, dio paso a lo que algunos autores denominan "guerras de tercera ola" 20 o "guerras del ordenador"21, llevadas a cabo por tropas altamente

${ }^{16}$ Elena del Mar García Rico, El Derecho Internacional Humanitario ante la doctrina de las "zero casualties warfare (en Víctor Gutiérrez Castillo y Alfredo Langa Herrero, coords: Los conflictos armados en la era de la globalización, Sevilla, 2007), pp. 133-34.

${ }^{17}$ En palabras de Smith, "the capacity to carry out surgical strikes opens a legal divide between technological haves and have-nots": vid. Thomas W. Smith, The New Law of War: Legitimizing HiTech and Infrastructural Violence, "International Studies Quarterly", 46 (2002), p. 362.

${ }^{18} \mathrm{La}$ importante desigualdad entre Estados con diferente acceso a las tecnologías de la información ha sido ampliamente examinada por James Adams, The Next World War: Warrior and Weapons of the New Battlefields of Cyberspace, Londres, Hutchinson,1998.

19 Vid. al respecto Richard Falk, The Role of Knowledge in the Cyber-Age of Globalisation, disponible en http://www.diplomacy.edu/resources/general/role-knowledge-cyber-age-globalisation.

${ }^{20}$ Alvin y Heidi Toffler, Las guerras del futuro, Barcelona, Plaza \& Janés, 1994, p 251.

21 Óscar Jaime-Jiménez, Riesgos y respuestas desde la seguridad de un mundo "glocalizado", Madrid, Biblioteca Nueva, 2004, p. 147. 
especializadas y en las que la tecnología ocupa un lugar destacado, para referirse a los principales conflictos armados de carácter internacional que han tenido lugar en las últimas décadas ${ }^{22}$.

El primer conflicto armado donde resultó patente la diferencia abismal que puede separar a los beligerantes, desde el punto de vista de su capacidad tecnológico-militar, fue la llamada Primera Guerra del Golfo desarrollada a principios de los años noventa del siglo pasado tras la invasión de Kuwait por Irak; si bien la intervención armada de la OTAN en el territorio de la antigua República Federativa de Serbia-Montenegro en la primavera de 1999 es la que "más se ajusta a semejante patrón en su sentido más puro" ${ }^{23}$. Asimismo cabría añadir a este listado el uso de la fuerza armada contra Afganistán por parte de los Estados Unidos en el marco de la Operación Libertad Duradera tras los terribles atentados del 11 de septiembre de 2001 y, finalmente, la intervención militar contra Irak iniciada el 19 de marzo de 2003 liderada por este mismo país ${ }^{24}$.

En este nuevo escenario internacional, y a partir de esa nueva realidad ligada a los avances tecnológicos en el ámbito militar, se elaboraron diferentes doctrinas o estrategias militares, entre las que sin duda destaca, por las consecuencias prácticas a las que acabamos de aludir, las denominadas "zero casualty wars" 25 o "guerras de coste cero" 26 , donde el contendiente mejor preparado tecnológicamente tiene capacidad para elegir los medios a través de los cuales causar graves daños al enemigo, y ello sin quedar especialmente expuesto a una respuesta por parte de éste que le cause gran número de bajas o suponga grandes costes militares ${ }^{27}$.

22 Para un análisis de la práctica internacional desde esa perspectiva, vid. Elena del Mar García Rico, El Derecho Internacional Humanitario ante la doctrina de las “zero casualties warfare” ,op. cit., pp. 134-142.

${ }_{23}$ En opinión, que compartimos, de Federico Aznar Fernández-Montesinos y Andrés González Martí, Las generaciones de guerra. Guerras de segunda y tercera generación (II), op. cit., p. 21.

${ }^{24}$ En el marco de la Operación Libertad para Irak, que el entonces presidente norteamericano, George W. Bush dio por terminada el 1 de mayo de 2003, tras 22 días en los que se acabó con el régimen de Sadam Hussein y se ocupó la totalidad del territorio iraquí.

25 Algunos autores utilizan la expresión "zero-casualty warfare", como ocurre con Anthony P.V. Rogers, Zero-casualty warfare, "International Review of the Red Cross", 82 (2000), p. 165-181. En cualquier caso, nos encontramos ante un término de eminente carácter doctrinal, con escaso éxito entre las autoridades militares y los códigos penales militares de los países de nuestro entorno.

${ }^{26}$ Con este término se hace referencia a la "estrategia político-militar surgida a finales del siglo pasado en el contexto de determinados conflictos armados que tienen en común haber sido iniciados por Estados Unidos y algunos de sus aliados, esto es, por países con gran capacidad tanto militar como económica, contra Estados que no tienen igual o similar nivel de desarrollo": vid. GARCÍA RICO, E.M., "El Derecho Internacional Humanitario ante la doctrina de las "Zero Casualties warfare”, op. cit. 126 .

27 Elena del Mar García Rico, Los conflictos armados del siglo XXI: ¿nuevos conflictos viejas normas? (en José Martín y Pérez de Nanclares, coord.: Estados y Organizaciones Internacionales ante las nuevas crisis globales, Madrid, 2010), p. 513. 
Las “guerras de coste cero", por tanto, están muy vinculadas a los avances tecnológico-militares producidos en los últimos años, así como al uso de medios y métodos de combate considerados más apropiados y capaces de conseguir un objetivo que, en contra de los tradicionales fines de cualquier conflicto armado, no es el de infligir el mayor número posible de bajas al enemigo o daños que le resulten insoportables, sino derrotarlo con el mínimo posible de pérdidas o costes en vidas humanas. Un objetivo que puede considerarse plenamente conforme con las obligaciones que los principios de necesidad y humanidad imponen y sobre los cuales se asienta el Derecho Internacional Humanitario.

No obstante, conviene tener presente el dato relativo a que, a tenor de cómo surgieron, las llamadas "guerras de coste cero" no implicaban o suponían la ausencia de cualquier tipo de bajas, sino sólo de aquellas que previsiblemente sufrirían las tropas y efectivos del ejército atacante, esto es, "cero bajas" para el contendiente técnicamente más adelantado, con independencia de si ello suponía graves pérdidas para un enemigo con menor capacidad tecnológicomilitar. De este modo, lo que en principio podría parecer como un objetivo totalmente conforme con las normas y principios básicos del DIH: minimizar la pérdida de vidas humanas, puede convertirse en una actividad totalmente contraria al mismo cuando ese objetivo se persigue a través de la utilización de medios y métodos de combate que no garantizan, o incluso incrementan, las cifras de bajas entre la población civil del Estado contra el que se lanza este tipo de ataques ${ }^{28}$.

La existencia de una variada gama de medios y métodos de combate adecuados para garantizar una guerra "limpia y rápida" ${ }^{29}$ constituye un requisito indispensable para el desarrollo de este tipo de conflicto armado pero no el único; por el contrario, las "zero casualty wars" dependen no sólo de este factor técnico-militar, sino también de aquel otro que pertenece al ámbito "políticointernacional". Con la mención a este último, queremos aludir al hecho de que este nuevo modelo de intervención armada en el exterior, al tratar de buscar el beneplácito de la población de los Estados "high-tech" para llevarlas a cabo, condujo a sus líderes a exigir la elaboración y puesta en práctica de estrategias militares encaminadas a reducir o evitar las bajas propias ${ }^{30} \mathrm{y}$, por consiguiente, un menor rechazo de la opinión pública internacional hacia una utilización de la fuerza no amparada por Naciones Unidas.

Así pues, las "guerras de coste cero" no implican o suponen la ausencia de cualquier tipo de bajas, sino sólo de aquellas que previsiblemente sufrirían las tropas y efectivos del ejército atacante, esto es, "cero bajas" para el contendiente

${ }^{28}$ Como apuntábamos en Elena del Mar García Rico, El Derecho Internacional Humanitario ante la doctrina de las "zero casualties warfare”, op. cit., p. 130.

29 Por utilizar una expresión ya empleada por Michael Ignatieff, The Virtual Commander: How NATO Invented a New Kind of War, en New Yorker, August 2, 1999, p. 36.

${ }^{30}$ Vid. A.P.V. Rogers, Zero-casualty warfare, op. cit., p. 165. 
técnicamente más adelantado, con independencia de si ello supone graves pérdidas para un enemigo con menor disponibilidad de altas tecnologías de carácter militar ${ }^{31}$.

Ahora bien, hemos de convenir que el desarrollo de este tipo de conflictos no conduce necesariamente en la práctica a la derrota a manos del contendiente tecnológicamente mejor preparado. Por el contrario, si algo nos demuestran los conflictos armados de Afganistán e Irak es que si bien en su fase inicial los Estados Unidos y sus aliados obtuvieron rápidas y destacadas victorias militares, no sólo no se ha logrado acabar con la situación que dio origen a estos conflictos sino que éstos se han prolongado en el tiempo hasta nuestros días.

Como se ha apuntado, "se piensa que la tecnología es la que permitirá obtener la victoria en esta nueva era de caos; en la era de la información, los sistemas digitales y las comunicaciones vía satélite, los nuevos sistemas de mando y control, las capacidades de obtener, almacenar y procesar información y las herramientas de planeamiento computerizadas, todo ello sumado a la creación de nuevas armas más poderosas, permitirá vencer no solo en las batallas, sino también en la guerra" ${ }^{32}$.

Sin embargo, añadiríamos a continuación, la realidad es bien distinta ${ }^{33}$, y nos muestra cómo los Estados "high-tech" se han mostrado incapaces de doblegar a un beligerante tecnológicamente inferior en lo que para algunos supone un nuevo tipo de guerra, denominada de "cuarta generación" 34 , en la que ejércitos dotados de altas tecnologías se enfrentan a fuerzas irregulares que disponen de medios de combate muy inferiores.

De este modo, los cambios experimentados por los conflictos armados en el siglo XXI vendrían de la mano no sólo de las altas tecnologías y su desigual distribución entre los componentes de la sociedad internacional actual, sino también de aquel otro elemento que apunta a la presencia cada vez más habitual en los mismos de actores no estatales.

${ }^{31}$ En palabras de FALK, "zero casualties for the high tech side, but unlimited vulnerability to devastation by a low tech adversary", vid. Richard Falk, The Role of Knowledge in the Cyber-Age of Globalisation, op. cit., p. 3.

${ }^{32}$ Vid. Pedro Sánchez Herráez, Guerras de cuarta generación. La solución: ¿tecnología?, "Revista Ejército", 282 (2008), p. 22.

${ }^{33}$ En palabras acertadas que compartimos, "es cierto que la tecnología - como cualquier otra herramienta - constituye un factor multiplicador, y nada desdeñable; pero no es menos cierto que ni la superioridad militar ni la tecnológica garantizan, per se, nada": ibídem, p. 23.

34 El término "guerras de cuarta generación" surgió en los círculos militares estadounidenses a finales de los años ochenta del siglo XX y su contenido ha evolucionado en especial tras los atentados de septiembre de 2011. Vid. William S. Lind; Keith Nightengale; John F. Schmitt; Joseph W. Sutton (USA); Gary I. Wilson, The Changing Face of War: Into the Fourth Generation, Marine Corps Gazette, 1989, disponible en http://www.lesc.net/system/files/4GW+Original+Article+1989.pdf; William S. Lind, Understanding Fourth Generation War, "Military Review", 2004; Thomas X. Hammes, War Evolves into the Fourth Generation, "Contemporary Security Policy", 26 (2005); William L. Miller y Morris Langdom, Fourth generation R\&D: Managing knowledge, technology, and innovation. John Wiley \& Sons, 2008; recientemente, William S. Lind \& Gregory A. Thiele, 4th Generation Warfare Handbook, Finlandia, Castalia House, 2015. 
La participación de grupos armados al margen de los ejércitos regulares, no obstante, a pesar de constituir un aspecto relativamente reciente no puede calificarse como algo insólito. Las guerras de liberación colonial son buena prueba de ello ${ }^{35}$, como también el dato que apunta a la progresiva desaparición de la distinción entre conflictos armados internacionales e internos propiciada por la jurisprudencia del Tribunal Penal para la Antigua Yugoslavia y Ruanda o de la Corte Penal Internacional.

Lo que sí constituye una auténtica novedad, en nuestra opinión, es el aumento no sólo cuantitativo sino también cualitativo de actores no estatales que se detecta en los conflictos armados de cuarta generación y constituyen un signo característico del siglo XXI. Actores que, como tendremos ocasión de comprobar, no dudan en emplear asimismo las nuevas tecnologías en su beneficio.

Esta confluencia de factores, esto es, la celeridad en los avances tecnológicos y el desigual acceso a éstos por parte de los beligerantes, unido a la inclusión entre ellos de actores no estatales, se encuentra también detrás de las llamadas "guerras asimétricas", que los analistas militares equiparan a las mencionadas guerras de cuarta generación, en referencia a aquellos conflictos armados que se desarrollan entre ejércitos estatales y actores no estatales y suponen la pérdida del monopolio de la fuerza o del uso de la fuerza internacional por parte de los Estados ${ }^{36}$.

La determinación y alcance exacto de la noción de conflicto asimétrico, sin embargo, no resulta fácil debido a la existencia de variadas y numerosas definiciones no sólo en el ámbito doctrinal ${ }^{37}$ sino especialmente en el político-militar, donde fueron elaboradas en el contexto de la "guerra global contra el terror" lanzada por la administración estadounidense tras los atentados del 11 de septiembre de $2001^{38}$. En cualquier caso, resulta evidente que esta noción aparece ligada a la de "guerras de cuarta generación" y ha evolucionado merced al cambio radical en la estrategia militar de Estados Unidos ${ }^{39}$ posterior a la guerra fría como consecuencia de la necesidad de elaborar respuestas apropiadas a un tipo de amenazas hasta ese momento no percibidas como tales ${ }^{40}$.

${ }^{35}$ Hasta el punto de que fueron objeto de regulación específica en el Protocolo I, de 8 de junio de 1977, Adicional a los Convenios de Ginebra de 1949, relativo a la protección de las víctimas de conflictos armados internacionales.

${ }^{36}$ En opinión, que compartimos, de John W. Bellflower, 4th Generation Warfare, "Small Wars Journal", 4 (2006), p. 28.

${ }^{37}$ Como señalan Pedro Fatjó y Guillem Colom, La guerra asimétrica: Olvidando la historia (en Carlos Cueto, coord.: Los desafios de las Fuerzas Armadas en el siglo XXI, Granada, Comares, 2008), pp. 65-74.

38 Vid. Elena del Mar García Rico, Los conflictos armados del siglo XXI: ¿nuevos conflictos viejas normas?, op. cit., p. 514.

39 Sobre el particular, Raúl Zelik, La Guerra Asimétrica. Una lectura crítica de la transformación de las doctrinas militares occidentales, "Estudios Políticos", 39 (2011), disponible en http://www. scielo.org.co/pdf/espo/n39/n39a08.pdf.

${ }^{40}$ U.S. Department of Defense. Quadrennial Defense Review Report.2001, disponible en http:// archive.defense.gov/pubs/qdr2001.pdf. 
En definitiva, nos encontramos ante una diversidad de aproximaciones a este tipo de conflicto armado $^{41}$ de la que, sin embargo, resulta posible deducir un conjunto de elementos comunes que nos permite sostener que las guerras o conflictos asimétricos se caracterizan por una desigualdad entre las partes tan manifiesta y suficientemente importante como para romper con el principio de igualdad y reciprocidad que subyace a la propia regulación de los conflictos armados, ya que desde el momento en que una de las partes es consciente de que es muy superior a la otra y viceversa, existe la tentación de considerar que no es necesario cumplir las normas que limitan los medios y métodos de guerra porque no existe la seguridad de que la otra parte vaya a cumplirlas ${ }^{42}$.

Desde esa perspectiva, no resulta extraño que el fenómeno de los conflictos asimétricos se haya puesto también en relación con los avances tecnológicos en el ámbito militar, en especial, los producidos por las nuevas tecnologías de la información ${ }^{43}$. Cobra forma así uno de sus principales rasgos, que surge cuando una de las partes es consciente de su superioridad tecnológico-militar respecto de la otra y, en sentido contrario, de la situación de inferioridad de esta última, con el nefasto resultado de que ambas llegan al convencimiento de que no es necesario cumplir las normas del DIH que limitan los medios y métodos de guerra.

De este modo, en el transcurso de estos conflictos asimétricos, "la parte más débil puede considerar necesario recurrir a métodos y medios ilícitos de combate para conseguir reequilibrar la balanza, convirtiendo en objetivo principal golpear al adversario allí donde no lo esperaría por estar prohibido, ocasionando graves daños con los medios de que dispone, especialmente a la población y objetivos de carácter civil"44, lo que constituye una clara violación del principio fundamental del Derecho Internacional Humanitario de distinción entre población civil y combatientes, así como entre objetivos militares y civiles ${ }^{45}$. Por su parte, el contendiente mejor situado podría utilizar

${ }^{41}$ Entre la abundante bibliografía que se ocupó de esta cuestión en sus orígenes, vid. Roger B. Arnett, Asymmetrical Warfare: Today's Challenge to US Military Power, Virginia, Potomac Books Inc, 2003; Barthélemy Courmont y Darko Ribnikar, Les guerres asymétriques, Paris, Presse Universitaire de France, 2002; Jacques Baud, La Guerre asymétrique ou la défaite du vainqueur, Paris, Editions du Rocher, 2003; Paul Rogers, Political Violence and Asymmetric Warfare, Washington, Brookings Institution, 2001.

42 Como sostuvimos en Elena del Mar García Rico, Problemas y desafios que los conflictos asimétricos plantean en el contexto del ius in bello (en Amérigo Cuervo-Arango, F. y Peñaranda Algar, J., coords: Dos Décadas de Posguerra Fría. Actas de las I Jornadas de Estudios de Seguridad de la Comunidad de Estudios de Seguridad "General Gutiérrez Mellado, Madrid, 2009), pp. 405-427.

${ }^{43}$ Como hizo en su momento Robert FALK, The Role of Knowledge in the Cyber-Age of Globalisation, op. cit.

${ }^{44}$ Ibídem, op. cit., p. 4.

${ }_{45}$ Consagrado en el artículo 48 del Protocolo Adicional I a los Convenios de Ginebra de 1949, en virtud del cual, "A fin de garantizar el respeto y la protección de la población civil y de los bienes de carácter civil, las Partes en conflicto harán distinción en todo momento entre población civil y combatientes, entre bienes de carácter civil y objetivos militares y, en consecuencia, dirigirán sus operaciones únicamente contra objetivos militares".

Araucaria. Revista Iberoamericana de Filosofía, Política y Humanidades, año 18, n 36. Segundo semestre de 2016. Pp. 265-293. ISSN 1575-6823 e-ISSN 2340-2199 doi: 10.12795/araucaria.2016.i36.12 
su superioridad tecnológica para hacer prevalecer sus objetivos aún cuando éstos pudieran no considerarse lícitos a tenor de los límites que este sector del ordenamiento internacional impone, a través de una reinterpretación o redefinición de dichos límites fundada precisamente en los rasgos más frecuentes de estos conflictos armados del siglo $\mathrm{XXI}^{46}$.

El resultado de esta dinámica supone, por tanto, que los contendientes pasan a tener diferentes objetivos y a emplear desiguales medios y métodos de combate en la puesta en práctica de sus tácticas y estrategias bélicas. De ahí a cuestionar el contenido y alcance de las normas fundamentales del DIH, ya sea por obsoletas, ya por ineficaces para hacer frente a lo que se considera una nueva forma de conflicto armado, queda un pequeño paso que algunos miembros de la sociedad internacional actual se han mostrado dispuestos a dar ${ }^{47}$.

En otro orden de consideraciones, hemos de reconocer que todo conflicto armado es asimétrico en la medida en que nunca dos beligerantes son iguales y que, como se apunta en la doctrina, esta asimetría está presente tanto a nivel operacional (perfidia, etc.), como estratégico-militar (guerra de guerrillas o represalias masivas) y político-social (guerras de religión, choque de civilizaciones $)^{48}$. Sin embargo, no cabe duda que en la actualidad los conflictos armados se han vuelto mucho más complejos y desiguales por la confluencia, como hemos señalado, de esos factores de cambio o novedades que aportan los avances tecnológicos y la multiplicación de actores internacionales no estatales que emplean los medios y métodos de combate que las altas tecnologías ponen a su alcance.

Las principales transformaciones experimentadas por los conflictos armados que acabamos de señalar, en fin, se encuentran asimismo en el origen y consolidación en los últimos años del concepto o la noción de "guerra híbrida" ${ }^{49}$, empleada por los estrategas militares ${ }^{50}$ y la doctrina esencialmente anglosajona para definir los conflictos armados de la presente centuria ${ }^{51}$.

${ }^{46}$ Vid. Elena del Mar García Rico, Los conflictos armados del siglo XXI: ¿nuevos conflictos, viejas normas?, op. cit., pp. 514-515.

${ }^{47}$ Ibídem, op. cit., p. 515.

48 Steven Metz, La guerre asymétrique et l'avenir de l'Occident, «Politique Étrangére», (2003), en pp. 30-33 ; en la misma línea, Jacques Baud, La guerre asymétrique ou la défaite du vainqueur, Mónaco, La Rocher, 2003.

${ }^{49}$ Expresión que en 2005 fue ya utilizada en la Estrategia Nacional de Defensa de Estados Unidos: vid. National Defense Strategy of the United States of America, Washington DC, U.S. Government Printing Office, 2005, disponible en http:/www.comw.org/qdr/fulltext/0503nds.pdf. Sobre el origen y evolución conceptual de la misma en la doctrina española, vid. Fabián Sánchez, El conflicto híbrido, ¿una nueva forma de guerra? (en El enfoque multidisciplinar a los conflictos híbridos, Madrid: CESEDEN, mayo 2012), pp. 11-24, disponible en http://www.defensa.gob.es/ceseden/Galerias/ destacados/publicaciones/docSegyDef/ficheros/051_EL_ENFOQUE_MULTIDISCIPLINAR_EN_ LOS_CONFLICTOS_HIBRIDOS.pdf.

${ }_{50}$ Así como en el seno de alianzas militares como la OTAN: véase en este sentido NATO, Wales Summit Declaration, Press Release (2014) 120, 05 de septiembre de 2014, párrafos 13 y 104. Disponible en http:/www.nato.int/cps/en/natohq/official_texts_112964.htm?selectedLocale=en.

51 Vid. al respecto la obra de James Mattis y Frank Hoffman, Future warfare: The rise of 
Unos conflictos que resultarían novedosos "tanto por los actores involucrados (Estados, grupos guerrilleros y terroristas, redes criminales o contratistas militares privados), como por los medios utilizados (armamento sencillo y asequible utilizado de forma novedosa, sistemas de armas altamente sofisticados o tecnologías de uso dual), las tácticas empleadas (acciones convencionales limitadas, actos terroristas, insurgencia, guerrillas u operaciones de información), los escenarios elegidos (desde zonas urbanas y densamente pobladas hasta lugares remotos o de difícil acceso), los multiplicadores utilizados (sistemas de posicionamiento y geolocalización, inteligencia de fuentes abiertas (OSINT) y de redes sociales (SOCMINT), redes de información, comunicaciones avanzadas e Internet) o las fuentes de financiación manejadas (desde actividades legales a actos delictivos con estrecha colaboración con el crimen organizado)" ${ }^{\prime 2}$.

Salvo en lo relativo al empleo de altas tecnologías por los beligerantes, sin embargo, los rasgos característicos que se acaban de enumerar no parece que resulten especialmente novedosos desde la perspectiva de la evolución de los conflictos armados y avalen la conveniencia de emplear el término "guerra híbrida" para referirse a los mismos ${ }^{53}$. De ahí que consideremos fundadas las críticas que ha suscitado el empleo de esta terminología, al igual que en su momento ocurrió respecto de la noción de "guerras asimétricas", con las que a menudo se equiparan las guerras o conflictos "híbridos" 54 .

En cualquier caso, hemos de convenir que la mayoría de los conflictos armados actuales se caracterizan por emplear de forma simultánea en el tiempo y el espacio, tanto por fuerzas o grupos armados irregulares como por los ejércitos estatales, medios y métodos de combate convencionales junto a otros

hybrid warfare, "U.S. Naval Institute Proceedings", 132 (2005); así como David Johnson, Military capabilities for hybrid war: Insights from the Israel Defense Forces in Lebanon and Gaza, Santa Monica, RAND Corporation, 2010, disponible en http://www.rand.org/content/dam/rand/pubs/ occasional_papers/2010/RAND_OP285.pdf; Frank Hoffman, Conflict in the 21st Century: The rise of hybrid wars, Arlington, Potomac Institute for Policy Studies, 2007; Brian Fleming, The Hybrid threat concept: Contemporary war, military planning and the advent of unrestricted operational art, Fort Leavenworth, U.S. Army Command and General Staff College, 2011, disponible en https://www. researchgate.net/publication/235168761_Hybrid_Threat_Concept_Contemporary_War_Military_ Planning_and_the_Advent_of_Unrestricted_Operational_Ārt; Williamson Murray y Peter Mansoor, Hybrid Warfare, Fighting $\bar{C}$ Complex Opponents from the Ancient World to the Present, Nueva York, Cambridge University Press, 2012.

${ }^{52}$ En palabras de Guillem Colom Piella, ¿El auge de los conflictos híbridos?, op. cit., pp. 3-4.

${ }^{53}$ Que compartimos en gran medida; vid. al respecto Russell Glenn, Thoughts on Hybrid Conflict, "Small Wars Journal”, 13 (2009), p. 8. Unas críticas a las que se han referido en nuestro país Guillem Colom Piella, ¿El auge de los conflictos híbridos?, op. cit., p. 11 y Josep Baqués Quesada, Las guerras híbridas: un balance provisional, "Boletín Electrónico del Instituto Español de Estudios Estratégicos, Documento de Trabajo 1/2015, p. 13-14; en la misma línea, vid. Pedro Sánchez Herráez, La nueva guerra hibrida: un somero análisis estratégico, Documento de análisis 54/2014, disponible en http:// www.ieee.es/Galerias/fichero/docs_analisis/2014/DIEEEA54-2014_NuevaGuerraHibrida_PSH.pdf.

${ }^{54}$ Vid. Josef Schroefl y Stuart Kaufman, Hybrid Actors, Tactical Variety: Rethinking $\overline{\text { Asymmetric }}$ and Hybrid War, "Studies in Conflict \& Terrorism", 37 (2014), pp. 862-880. 
que no lo $\operatorname{son}^{55}$ gracias a las posibilidades que la era de la información ofrece ${ }^{56}$ y al empleo de armamento y material tecnológicamente muy avanzado ${ }^{57}$, tales como aviones no-tripulados o sistemas de comunicación e informáticos, entre otros, sobre los que centraremos nuestra atención en el siguiente apartado.

\section{Las altas tecnologías y los nuevos métodos y medios de combate}

Como señalábamos en las páginas introductorias del presente estudio, las nuevas tecnologías de guerra también se encuentran ligadas a las amenazas para las personas y comunidades que se derivan de los múltiples conflictos armados que se desarrollan en la sociedad internacional contemporánea y plantean auténticos retos humanitarios a los que no resulta en modo alguno ajena la noción de seguridad humana.

En este sentido, resulta evidente que los avances tecnológicos influyen cada vez más en la manera en que se usa la fuerza en las relaciones internacionales así como que, entre las altas tecnologías surgidas en los últimos años, el desarrollo en particular de las capacidades militares cibernéticas y los sistemas de armas autónomos, suscitan gran interés humanitario a la vez que cuestiones relacionadas con la adecuación del DIH a las características específicas de estos avances.

Situados en esta perspectiva, no cabe duda que los rápidos logros alcanzados en la llamada era de la información han favorecido el surgimiento y consolidación del ciberespacio como un fenómeno multidimensional y transformador no sólo de las relaciones internacionales políticas y económicas sino también de las militares ${ }^{58}$, de tal manera que el uso hostil del mismo ha venido a ocupar un lugar destacado entre las preocupaciones de seguridad no sólo de los gobiernos, sino también de los particulares, empresas y otros actores internacionales.

De este modo, a la generación de nuevas modalidades de conflictos no convencionales mencionados ut supra vendría a sumarse "la potencialidad

\footnotetext{
${ }^{55}$ A los que Hoffman añade las acciones terroristas y el crimen organizado: vid. Frank G. Hoffman, Future Hybrid Threats: An Update, Center for Strategic Research, Institute for National Strategic Studies, Washington DC, 2012, p. 2.

56 Josep Baqués Quesada, Las guerras híbridas: un balance provisional, op. cit., p. 12.

57 Y no sólo por parte de los Estados "high-tech", como apunta Brian Fleming, The Hybrid threat concept: Contemporary war, military planning and the advent of unrestricted operational art, op. cit., p. 25.

${ }_{58}$ Hasta el extremo de ser considerado un nuevo dominio de guerra que modifica los parámetros de defensa convencionales y donde, como se ha señalado, "incluso era difícil determinar qué constituye un ataque y qué no, donde acaban los actos de espionaje o intrusiones malintencionadas y dónde empieza lo que puede definirse como un acto de guerra": Eguskiñe Lejarza Illaro, Ciberguerra, los escenarios de confrontación, "Boletín Electrónico del Instituto Español de Estudios Estratégicos", Documento de Opinión 18/2014, p. 6.
} 
que ofrece el ciberespacio para que un único sujeto, desde cualquier lugar y con escasos medios pueda llegar a alcanzar una capacidad delictiva e, incluso, destructiva inimaginable en el mundo precibernético" "59, lo que contribuye a acrecentar la sensación de inseguridad entre actores estatales y no estatales.

En este contexto parece encontrar acomodo la expresión "ciberguerra", empleada con profusión tanto en el ámbito doctrinal ${ }^{60}$ como estratégico-militar para referirse a las transformaciones que este nuevo dominio o escenario de conflicto $^{61}$ ha supuesto en la propia naturaleza y características de los conflictos armados contemporáneos ${ }^{62}$.

Mas al margen de su consideración o no como elemento presente en estos $\operatorname{conflictos}^{63}$, consideramos que aunque el ciberespacio supone un avance tecnológico que conlleva novedades inherentes a la existencia, junto a los ya tradicionales de tierra, mar y aire, de un "campo de batalla virtual"64, el empleo de capacidades cibernéticas en una situación de conflicto armado, cualesquiera que éstas sean, debe adecuarse a las normas que en relación a los medios y métodos de guerra impone el principio fundamental del Derecho Internacional Humanitario en virtud del cual "en todo conflicto armado, el derecho de las partes en conflicto a elegir los métodos o medios de hacer la guerra no es ilimitado"65.

${ }^{59}$ En opinión, que compartimos, de Margarita Robles Carrillo, El ciberespacio y la ciberseguridad: consideraciones sobre la necesidad de un modelo jurídico, "Boletín Electrónico del Instituto Español de Estudios Estratégicos", Documento de Opinión 124/2015, p. 16.

${ }^{60}$ Vid. Adam P. Liff, Cyberwar: A New 'Absolute Weapon'? The Proliferation of Cyberwarfare Capabilities and Interestate War, "The Journal of Strategic Studies", 35 (2012), pp. 401-428, para quien esta expresión abarcaría toda situación de conflicto no necesariamente entre dos Estados, sino otros actores políticos, que se caracteriza por la ejecución de ataques deliberados, hostiles y dañinos contra redes de ordenadores en la infraestructura crítica civil y militar de un adversario orientada a la obtención de concesiones políticas, así como cualquier medida de fuerza bruta contra las redes militares o civiles con el fin de reducir la capacidad del adversario para defenderse o para llevar a cabo represalias semejantes o mediante fuerzas convencionales, o contra objetivos militares y/o civiles con objeto de afectar a un actor por motivos estratégicos, en pp. 405-8.

${ }^{61}$ William J. Lynn, Defending a New Domain, "Foreign Affairs", 80 (2010), pp. 97-108; Richard A. Clarke y Robert K. Knake, Guerra en la red. Los nuevos campos de batalla, Barcelona, Ariel, 2011.

${ }_{62}$ Como señala algún autor en relación con quienes defienden esta visión, "the emergence of Cyber warfare is more than just another evolutionary step in the development of wartime strategy and methodology; instead, they argue that it represents a fundamental transformation in the very nature of the concept of war itself. The notion that cyber warfare will alter the inherent nature of war is ultimately rooted in the conceptual idea that cyber warfare does not merely change the weaponry of modem wars, but that it represents a radical shift in the nature of the wartime battlefield": vid. Bradley Raboin, Corresponding Evolution: International Law and the Emergence of Cyber Warfare, "Journal of the National association of Administrative Law Judiciary", 31 (2011), p. 604.

${ }^{63}$ En opinión, que compartimos, del Comité Internacional de la Cruz Roja: vid. Cuarto informe sobre el derecho internacional humanitario y los desafios de los conflictos armados contemporáneos que el Comité Internacional de la Cruz Roja (CICR) presenta a la Conferencia Internacional de la Cruz Roja y de la Media Luna Roja (Conferencia Internacional) celebrada en diciembre de 2015, disponible en https://www. icrc.org/es/document/el-derecho-internacional-humanitario-y-los-desafios-de-los-conflictos-armados.

${ }^{64}$ Si bien con indudables repercusiones en la vida real, como señala Bradley Raboin, Corresponding Evolution: International Law and the Emergence of Cyber Warfare, op. cit., p. 604.

${ }^{65}$ Tal y como se recoge en el artículo 35.1 del Protocolo Adicional I a los Convenios de Ginebra de 1949, adoptado en 1977. 
De ahí que consideremos más apropiado centrar nuestra atención en los "ciberataques" $" 66$, en referencia a aquellas operaciones técnicamente posibles o acciones puntuales lanzadas por los Estados y/o grupos armados no estatales contra un ordenador o un sistema informático a través de una corriente de datos con el propósito de causar daños o perturbar el adecuado funcionamiento de un ordenador, un dispositivo de red o los objetos controlados por el sistema informático ${ }^{67}$ en una situación de un conflicto armado.

Si bien el potencial militar del ciberespacio está aún por determinar, en un escenario donde este tipo de capacidades adquieren relevancia en términos ofensivos y defensivos en las operaciones militares, consideramos que el examen de la conformidad de estas acciones con las normas del DIH requiera solventar ciertos problemas relacionados con la aplicación de este sector del ordenamiento jurídico-internacional ${ }^{68}$ a los desafíos que las altas tecnologías plantean en la actualidad.

Desafíos de orden jurídico y también humanitario, en la medida en que la protección de la infraestructura cibernética de la cual depende la infraestructura civil esencial de cualquier Estado relativa a los sistemas de transporte, las redes eléctricas, los diques, las plantas químicas o nucleares, resulta imprescindible para evitar las graves consecuencias sobre la población civil que conllevaría su destrucción ${ }^{69}$.

Unos retos que se plantean igualmente respecto de la protección de las capacidades cibernéticas de las que depende el potencial militar de cualquier beligerante, con independencia de si éste puede ser considerado un Estado o actor no estatal "hig-tech" ${ }^{70} \mathrm{O}$ "low-tech", en la medida en que la evolución de internet y su presencia intrusiva en la vida cotidiana de prácticamente cualquier ser humano sobre el planeta, no sólo hace más vulnerable a la sociedad internacional en su conjunto, sino que constituye un medio de combate especialmente idóneo para el contendiente técnicamente menos

${ }^{66}$ Vid. sobre el particular Scott Shackelford, From Nuclear War to Net War: Analogizing Cyber Attacks in International Law, "Berkeley Journal of International Law", 25 (2009), 191-251.

${ }^{67}$ Que se producirían, por consiguiente, no sólo en el marco de cualquier conflicto armado, ya sea este convencional o bien responda a los rasgos característicos de las denominadas ciberguerras.

${ }^{68}$ No en vano, este fenómeno suscita problemas para la interpretación y aplicación del derecho internacional humanitario relativos al "anonimato en el que se construye el ciberespacio; la falta de claridad con respecto a la aplicación del DIH a las operaciones cibernéticas en ausencia de operaciones cinéticas; el debate sobre la noción de "ataque" en el marco de las normas del DIH que rigen la conducción de hostilidades; y los desafíos para aplicar estas normas a la guerra cibernética, en particular la prohibición de los ataques indiscriminados y las normas sobre la precaución en el ataque": vid. Cuarto informe sobre el derecho internacional humanitario y los desafios de los conflictos armados contemporáneos que el Comité Internacional de la Cruz Roja (CICR) presenta a la Conferencia Internacional de la Cruz Roja y de la Media Luna Roja (Conferencia Internacional) celebrada en diciembre de 2015, op. cit., p. 53.

${ }^{69}$ Ibídem, pp. 51-2.

${ }^{70}$ Especialmente vulnerables por lo que a los centros de mando y los escalones de retaguardia se refiere, como apunta Manuel Torres, Los dilemas estratégicos de la ciber-guerra, "Revista Ejército", 2011, p. 16. 
avanzado debido a su fácil acceso, escasa o nula regulación, anonimato, bajo coste económico, rapidez y efectividad.

Junto a los problemas que suscitan las altas tecnologías en el ámbito de la informática y del ciberespacio, también debemos prestar atención en nuestro estudio al notable avance que en las últimas décadas se ha producido tanto en el desarrollo como en el uso de sistemas robóticos por las fuerzas armadas, sobre todo en lo que respecta a sistemas no tripulados que operan en el aire, en tierra y en el agua que, combinados con las demandas operacionales militares, han convertido en realidad la posibilidad antes impensable de reducir e incluso eliminar por completo el control humano directo sobre los sistemas de armas y el uso de la fuerza. Una circunstancia relativamente novedosa que en nuestra opinión puede dificultar la necesaria aplicación de las normas del DIH a los conflictos armados actuales.

No resulta extraño por tanto que la creciente automatización de los métodos de guerra $^{71}$ haya propiciado un interesante debate en foros diplomáticos, doctrinales y militares en torno a los llamados "sistemas de armas autónomos", entendiendo por tales "cualquier tipo de sistemas de armas, sea que operen en el aire, en la tierra o en el mar, con autonomía en sus "funciones críticas", esto es, un arma que puede seleccionar (es decir, buscar o detectar, identificar, seguir, seleccionar) y atacar (es decir, emplear la fuerza, neutralizar, dañar o destruir) objetivos sin intervención humana"72 más allá de la necesaria activación inicial del dispositivo de que se trate.

Aunque algunos de los sistemas de armas que se utilizan en la actualidad gozan ya de bastante autonomía en sus funciones críticas ${ }^{73}$, su operatividad suele reducirse a períodos cortos de tiempo, asignándoles tareas esencialmente defensivas y objetivos limitados en entornos simples y relativamente predecibles. Sin embargo, cabe prever que las ventajas que se predican respecto de dotar de una mayor autonomía a estos sistemas de $\operatorname{armas}^{74}$ favorecerán nuevos avances

\footnotetext{
${ }^{71}$ Al respecto resulta interesante la obra de Peter W. Singer, Wired for War: Robotics Revolution and Conflict in the 21th Century, Nueva York, Penguin Press, 2009.

${ }^{72}$ En términos propuestos por el CICR: vid. Cuarto informe sobre el derecho internacional humanitario y los desafios de los conflictos armados contemporáneos que el Comité Internacional de la Cruz Roja (CICR) presenta a la Conferencia Internacional de la Cruz Roja y de la Media Luna Roja (Conferencia Internacional) celebrada en diciembre de 2015, op. cit., p. 58. La cursiva es nuestra.

${ }^{73}$ Entre ellos, los sistemas de defensa aérea y antimisiles, los sistemas de armas de "protección activa" para vehículos terrestres, y los sistemas de armas de perímetro (a veces denominadas "armas centinelas"), así como las municiones de tipo "loitering” y los vehículos armados submarinos: ibídem, p. 59.

${ }^{74}$ Enumerados por algunos autores, y que incluirían: la necesidad de respuestas precisas e inmediatas que puedan salvar las vidas de combatientes propios; de liberar a los operadores humanos de la atención que exige el control de los robots militares; o evitar los fallos en la conexión entre robot y controlador humano, en su caso: vid. Javier Jordán y Josep Baqués, Guerra de Drones. Política, tecnología y cambio social en los nuevos conflictos, op. cit., pp. 138-9; Joseph W. Dyer, Robots make war more survivable, "Armed Forces Journal” (2007), pp. 26-9.
} 
tecnológicos en esta materia ${ }^{75}$, por lo que no parece descabellado vislumbrar la posibilidad de que en un futuro no muy lejano se confiera a los sistemas de armas autónomos más libertad de acción para determinar sus objetivos, operar fuera de límites espaciales y temporales rigurosamente restringidos, y reaccionar a circunstancias rápidamente cambiantes, planteando un desafío tecnológico con indudables implicaciones jurídicas y humanitarias.

En este sentido se han planteado dudas acerca de si resulta técnicamente posible programar estos sistemas de armas autónomos para que lleven a cabo las complejas evaluaciones que conlleva la aplicación de las normas del DIH sobre distinción, proporcionalidad y precaución en el ataque en contextos especialmente complejos como los que representan los conflictos armados actuales. Asimismo, se han puesto señalado las dificultades que la pérdida de control humano sobre los sistemas de armas autónomos pueden acarrear con vistas a la atribución de responsabilidad por la comisión de violaciones graves de esta rama del ordenamiento internacional a las personas involucradas en la programación y despliegue de los mismos.

En cualquier caso, hemos de convenir que la progresiva robotización de las fuerzas armadas ha adquirido un papel destacado en el contexto de los conflictos armados en la era de la información, en especial con la utilización de vehículos aéreos no tripulados, más conocidos popularmente como drones, "en tanto proveedores de inteligencia y, cada vez más, como plataforma de armas, amén de otras funciones"76.

A diferencia de los sistemas de armas autónomos que acabamos de mencionar $^{77}$, sin embargo, estos robots militares o vehículos aéreos no tripulados son el resultado de operaciones humanas y tecnológicas, por lo que sus funciones críticas son controladas a distancia por un operador humano y por tanto gozan de menor autonomía ${ }^{78}$.

Quizás por ello, y dado su potencial de uso en las más variadas facetas que ofrece a cualquier contendiente, su presencia en el campo de batalla se remota en el tiempo más de un siglo y han evolucionado al igual que los propios

${ }^{75}$ En particular, en lo relativo a la "comprensión del entorno, realización de juicios e interoperatividad con el resto de la fuerza": vid. Javier Jordán y Josep Baqués, Guerra de Drones. Política, tecnología y cambio social en los nuevos conflictos, op. cit., p. 144.

${ }^{76}$ En palabras de Javier Jordán y Josep Baqués: ibídem, p. 78.

${ }^{77}$ Que ha puesto de manifiesto de modo acertado el Comité Internacional de la Cruz Roja: vid. Cuarto informe sobre el derecho internacional humanitario y los desafios de los conflictos armados contemporáneos que el Comité Internacional de la Cruz Roja (CICR) presenta a la Conferencia Internacional de la Cruz Roja y de la Media Luna Roja (Conferencia Internacional) celebrada en diciembre de 2015, op. cit., p. 59.

${ }^{78}$ Es cierto, que como se ha señalado recientemente, "la tecnología va a ir avanzando y ya hay RPAS civiles que son capaces de realizar casi todas las operaciones básicas por sí mismos, pero por el momento esto no se ha dado en el sector militar y si se diera, provocaría un claro problema al derecho internacional al sacar al humano de las operaciones militares": vid. Borja Llandrés Cuesta, Los UAS, una valoración sobre su uso, "Boletín Electrónico del Instituto Español de Estudios Estratégicos", Documento de Opinión 134/2015, p. 8. 
conflictos armados, adaptándose a sus características y a las necesidades de los beligerantes ${ }^{79}$. Así, conviene mencionar cómo tras el salto cualitativo en el empleo de los drones al que asistimos en los años cincuenta y sesenta de la pasada centuria ${ }^{80}$, los avances tecnológicos alcanzados a finales del siglo XX propiciaron un desarrollo vertiginoso de estas plataformas aéreas que les permitía llevar misiles y, por tanto, ser empleados no sólo para labores de vigilancia y obtención de información, sino como medios efectivos de combate.

Estas innovaciones tecnológicas han dado lugar a la distinción entre los denominados vehículos aéreos no tripulados (o UAV), y los vehículos aéreos de combate no tripulados (o UCAV) ${ }^{81}$, convirtiéndolos en un elemento estratégico clave dada la naturaleza asimétrica de la mayor parte de los conflictos contemporáneos de los que nos ocupamos en el primer epígrafe de nuestro estudio.

En particular, y situado en el contexto de la actual lucha contra el terrorismo internacional, se ha apuntado que la utilización de drones contra Al Qaeda y otros grupos armados talibanes en numerosos ataques aéreos sobre las áreas fronterizas entre Afganistán y Pakistán a partir de $2004^{82}$ constituye la primera campaña aérea de la historia realizada exclusivamente por este medio de combate que, en determinadas circunstancias, tiene lugar en una situación de conflicto armado no internacional ${ }^{83}$.

En cualquier caso, si bien resulta evidente que este modelo de actuación armada no resulta fácil de aplicar a otros escenarios bélicos, inclusive los de carácter asimétrico ${ }^{84}$, su empleo en el supuesto antes mencionado ha permitido

${ }^{79}$ Para un análisis histórico de los robots militares resulta especialmente interesante consultar la obra de Javier Jordán y Josep Baqués, Guerra de Drones. Política, tecnología y cambio social en los nuevos conflictos, op. cit., pp. 15-47; por lo que se refiere a los drones, vid. también Bill Yenne, Attack of the Drones. A History of Unmanned Aerial Combat, St. Paul, Zennith Press, 2004; John David Blom, UAS: A Historical Perspective, "Combat Studies Institute Press", Kansas, (2010); Charles Jarnot, History (en Richard K. Barnhart; Stephen B. Hottman, Douglas M. Marshall y Eric Shappee, eds.: Introduction to Unmanned Aircraft Systems, Boca Raton, CRC Press, 2012), pp. 1-16.

${ }^{80}$ Como apuntan Javier Jordán y Josep Baqués, Guerra de Drones. Política, tecnología y cambio social en los nuevos conflictos, op. cit., p. 20 y Borja Llandrés Cuesta, Los UAS, una valoración sobre su uso, op. cit., p. 3.

${ }^{81}$ En siglas correspondientes a las expresiones en inglés "Unmanned Aerial Vehicles"y "Unmanned Combat Aerial Vehicles", respectivamente.

${ }^{82}$ Para un exhaustivo examen de la misma, vid. Javier Jordán y Josep Baqués, Guerra de Drones. Política, tecnología y cambio social en los nuevos conflictos, op. cit., pp. 81- 118.

${ }^{83}$ Coincidimos, en este aspecto, con quienes sostienen que no resulta admisible la utilización de la noción jurídico-internacional de conflicto armado, internacional o no internacional, llevada a cabo por Estados Unidos desde los atentados de septiembre de 2001: vid. Nehal Bhuta, States of Exception: Regulating Targeted Killing in a "Global Civil War" (en Philip Alston y Euan Mc Donald, eds.: Human Rights, Intervention and the Use of Force, Oxford, Oxford University Press, 2008), p. 259; Milena Sterio, The United States' Use of Drones in the War on Terror: The (I)legality of Targeted Killings Under International Law", "Case Western Reserve Journal of International Law", 45 (2012), p. 204; en nuestro país, Felipe Gómez Isa, Los ataques armados con drones en Derecho Internacional, "Revista Española de Derecho Internacional", 67 (2015), p. 85.

${ }^{84}$ Para lo cual resultaría necesario, además, en opinión de la doctrina que compartimos, la concurrencia 
constatar sobre el terreno las ventajas que desde una perspectiva militar ofrecen estos vehículos aéreos de combate no tripulados.

En este sentido merecen ser destacados entre otros aspectos ${ }^{85}$, la utilidad de los UAV para recabar y entregar información detallada sobre las fuerzas enemigas y realizar tareas de vigilancia de objetivos concretos; así como la capacidad casi instantánea de los UCAV para pasar a la acción ofensiva ${ }^{86}$ sin poner en peligro al personal militar durante el combate ${ }^{87}$ al tiempo que se elimina o reduce el factor fatiga de los pilotos por su capacidad para actuar durante largos períodos de tiempo; sin olvidar el dato relevante que apunta a su menor coste respecto a los aparatos aéreos tripulados ${ }^{88}$.

Ahora bien, el empleo de este medio de combate también presenta inconvenientes derivados de factores técnicos y humanos ${ }^{89}$. Entre los primeros, se incluirían tanto los problemas mecánicos como aquellos relacionados con la conexión entre los UAV y la estación central de control, así como las limitaciones derivadas de sus propias características si los comparamos con los aviones de combate $^{90}$. Además, el empleo de la técnica denominada “doubletap", que consiste en el lanzamiento de dos misiles para asegurar la neutralización del objetivo, provoca bajas entre los civiles y los servicios sanitarios o de ayuda que se acercan a la escena del ataque y sobre los cuales impacta a menudo el segundo misi191.

El coste en bajas civiles ${ }^{92}$ provoca, por otro lado, un lógico rechazo en las comunidades locales y favorece una opinión pública contraria a quienes los

de diversas condiciones añadidas: superioridad aérea incontestada por parte del Estado tecnológicamente mejor situado; un número relativamente reducido de adversarios poco arraigados socialmente; una actuación que se prolongue durante varios años y apoyada por las opiniones públicas de los países afectados; así como unas excelentes capacidades de inteligencia sobre del terreno: vid. Javier Jordán y Josep Baqués, Guerra de Drones. Política, tecnología y cambio social en los nuevos conflictos, op. cit., pp. 120-122.

${ }^{85}$ Bradley Strawser, Moral Predators: The Duty to Employ Uninhabited Aerial Vehicles, "Journal of Military Ethics", 9 (2010), pp. 342-368.

${ }^{86}$ Debido a los sensores instalados en su interior, el drone "permite localizar rápidamente e identificar a los posibles objetivos y marcar su posición a través de un láser que guiará al misil hasta el objetivo", como ha señalado Borja Llandrés Cuesta, Los UAS, una valoración sobre su uso, op. cit., p. 5.

${ }^{87}$ Un objetivo que, como vimos en otro lugar de nuestro estudio, se persiguen en las llamadas "guerras de coste cero": en este sentido, vid. Joseph W. Dyer, Robots make war more survivable, op. cit., pp. 26-29.

${ }_{88}$ A la que se refiere de forma detallada Borja Llandrés Cuesta, Los UAS, una valoración sobre su uso, op. cit., p. 7.

${ }^{89}$ Vid. Patrick Lin; George Bekey y Keith Abney, Autonomous Military Robotics: Risk, Ethics, and Design, San Luis Obispo, California Polytechnic State University, 2008.

${ }_{90}$ Que pueden llevar a cabo misiones más amplias y variadas, con mayor rapidez y maniobrabilidad que los UAV.

${ }_{91}$ Como señala Borja Llandrés Cuesta, Los UAS, una valoración sobre su uso, op. cit., p. 9.

${ }_{92}$ En opinión de algunos autores en relación con el empleo de drones en suelo afgano, "a pesar de que la proporción de bajas civiles se ha reducido en los últimos años, y de que es menor que la que habrían provocado los bombardeos de aviones tripulados, su número total (incluso en las estimaciones menos elevadas) desenmascara cualquier intento de presentar la guerra de drones como un conflicto aséptico, capaz de delimitar con exactitud los efectos de la violencia”, Javier Jordán y Josep Baqués, Guerra de Drones. Política, tecnología y cambio social en los nuevos conflictos, op. cit., p. 170. 
utilizan, sin que ello suponga garantizar que los operadores de los drones de combate escapen al síndrome de estrés post traumático ligado tradicionalmente a los soldados en el frente de guerra ${ }^{93}$.

En otro orden de consideraciones, el hecho de que los UAV sean operados a gran distancia del objetivo situado en tierra hostil, aun cuando elimina o reduce considerablemente el número de bajas en el contendiente tecnológicamente mejor preparado, y precisamente por ello, puede llegar a facilitar e incluso predisponer positivamente a los mandos militares y políticos respecto del recurso a la fuerza ${ }^{94} \mathrm{o}$, si está ya se está empleando, a prolongarla en el tiempo ${ }^{95}$.

A pesar de ello, hemos de reconocer que los avances tecnológicos y las capacidades técnicas de los drones en la actualidad no los convierte per se en un medio de combate contrario a las normas del Derecho Internacional Humanitario que les resultan de aplicación en los supuestos de conflicto $\operatorname{armado}^{96}$.

Por el contrario, se ha considerado que la notable precisión de los drones y su capacidad de vigilancia durante largos períodos de tiempo benefician el cumplimiento de la obligación fundamental de distinción entre objetivos militares y civiles $^{97}$, si bien aquélla depende en gran medida de la exactitud de las fuentes de inteligencia humana desplegadas sobre el terreno sobre la que se basa la decisión de seleccionar un determinado objetivo, no siempre fiables ${ }^{98}$. Asimismo, la capacidad para dirigir el ataque con drones de forma bastante precisa se muestra como un magnífico aliado para limitar al máximo

${ }_{93}$ Ibídem, p. 156 y Borja Llandrés Cuesta, Los UAS, una valoración sobre su uso, op. cit., p. 6.

${ }^{94} \mathrm{Y}$ puede contribuir a una interpretación excesivamente amplia del concepto de necesidad militar, en opinión que compartimos de Pilar Pozo, La utilización de los drones en los conflictos actuales: una perspectiva del derecho internacional, "Boletín Electrónico del Instituto Español de Estudios Estratégicos", Documento de opinión 37/2011, p. 3; así como a una "cierta des-sensibilización y a una "mayor propensión a matar", como apunta Felipe Gómez Isa, Los ataques armados con drones en Derecho Internacional, op. cit., p. 70.

95 "Sine die, siempre que la economía lo permita. Y ya no digamos en el caso de que los intereses económicos en liza así lo requieran”, en palabras de Javier Jordán y Josep Baqués, Guerra de Drones. Política, tecnología y cambio social en los nuevos conflictos, op. cit., p. 164. La cursiva es de los autores.

${ }^{96}$ Una posición que comparte la mayoría de la doctrina, como destaca Felipe Gómez Isa, Los ataques armados con drones en el derecho internacional, op. cit., p. 73 y Pilar Pozo, La utilización de los drones en los conflictos actuales: una perspectiva del derecho internacional, op. cit., p. 7. Vid. asimismo Milena Sterio, The United States' Use of Drones in the War on Terror: The (I)legality of Targeted Killings Under International Law, op. cit., p. 209; Christof Heyns, Informe del Relator Especial sobre las ejecuciones extrajudiciales, sumarias o arbitrarias, Documento de N.U. A/68/382, p. 4, disponible en http://daccess-dds-ny.un.org/doc/UNDOC/GEN/N13/473/63/PDF/N1347363. pdf?OpenElement.

97 Vid. Patrick Lin; George Bekey y Keith Abney, Autonomous Military Robotics: Risk, Ethics, and Design, op. cit., p. 52-53; Cheri Kramer, The Legality of Targeted Drone Attacks as US Policy, op. cit., p. 381 .

98 A lo que se añade los problemas derivados de la diferencia entre el movimiento que se produce sobre el terreno y la llegada de la imagen de vídeo al piloto del dron que se produce vía satélite, "lo que técnicamente se conoce como "latencia", como apunta Felipe Gómez Isa, Los ataques armados con drones en el derecho internacional, op. cit., p. 68-9. 
los posibles daños colaterales entre la población civil y respetar el principio de proporcionalidad que siempre debe guiar la acción de toda parte en un conflicto $\operatorname{armado}^{99}$. Todo lo cual facilitaría, en definitiva, el cumplimiento del DIH.

Ahora bien, tal y como ocurre con cualquier medio de combate, la conformidad del empleo de drones con las normas que conforman este sector del ordenamiento internacional sólo puede afirmarse tras el análisis de cada una de las situaciones de conflicto y a la vista de los elementos que concurran en las mismas, por lo que no resulta posible realizar afirmaciones genéricas acerca de la legalidad o no del mismo.

De ahí, en particular, las críticas que en los últimos años han suscitado los denominados "ataques selectivos" o "signature strike" llevados a cabo con UCAV por Estados Unidos o Israel contra individuos considerados terroristas o miembros de grupos insurgentes, ya sea porque así lo señalan las fuentes de inteligencia, ya porque las labores de vigilancia desarrolladas por los UAV.

$\mathrm{Al}$ respecto, comparto la opinión de quienes consideran que "los ataques basados en imprecisos patrones de comportamiento y no en la participación directa en las hostilidades o en la condición de miembro de un grupo armado, no sólo constituyen una brecha en la línea de flotación del principio de distinción, sino que quedan muy lejos "de las precauciones y presunciones que se deben aplicar en caso de duda" 100 .

Además, constituiría en nuestra opinión una flagrante violación del artículo 3 común a las cuatro Convenciones de Ginebra de $1949^{101}$, que protege a todas aquellas personas que no participan directamente en las hostilidades y recoge, en opinión de la Corte Internacional de Justicia ${ }^{102}$, las más elementales consideraciones de humanidad que deben ser observadas en todo tipo de conflictos armados como parte del derecho internacional consuetudinario ${ }^{103}$.

\footnotetext{
${ }^{99}$ Como ha señalado Lauri R. Blank, After “Top Gun”: How Drone Strikes Impact the Law of War, "University of Pennsylvania Journal of International Law”, 33 (2012), p. 697.

${ }^{100}$ Felipe Gómez Isa, Los ataques armados con drones en el derecho internacional, op. cit., p. 88.

101 En particular, de su apartado 1.d), referido a las llamadas ejecuciones extrajudiciales, cuando prohíbe "las condenas dictadas y las ejecuciones sin previo juicio ante un tribunal legítimamente constituido, con garantías judiciales reconocidas como indispensables por los pueblos civilizados".

${ }^{102}$ En su ya célebre pronunciamiento con ocasión de sus Sentencia en el Asunto de las actividades militares y paramilitares en y contra Nicaragua: vid. Military and paramilitary activities in and against Nicaragua (Nicaragua v. United States of America), Mérits, Judgment, I.C.J. Reports 1986, para. 218.

${ }_{103}$ Como sostuvimos en su momento: vid. Elena del Mar García Rico, Los conflictos armados del siglo XXI: ¿Nuevos conflictos, viejas normas?, op. cit., p. 519.
} 


\section{Conclusiones}

El carácter multidimensional inherente al concepto de seguridad humana conlleva en nuestra opinión la conveniencia de examinar las amenazas existentes y emergentes para la seguridad y el bienestar de las personas y las comunidades, incluidas aquellas que se derivan de las consecuencias que la utilización de altas tecnologías puedan ocasionar en relación con los conflictos armados que se suceden en la sociedad internacional contemporánea.

En este sentido, hemos podido constatar en nuestro estudio cómo los avances tecnológicos han propiciado cambios relevantes en la naturaleza y características de los conflictos armados del siglo XXI, al tiempo que plantean retos humanitarios y jurídicos de la mano del surgimiento de nuevos métodos y medios de guerra ligados a las altas tecnologías.

Así, cabe apuntar a la creciente y rápida incorporación de las tecnologías de la información y al desarrollo de formas más descentralizadas de organización militar en el seno de una sociedad permanentemente interconectada como elementos que han provocado una auténtica revolución en los asuntos militares y transformado algunos rasgos habituales de los conflictos armados.

En la misma línea, se puede afirmar que el nivel tecnológico de los beligerantes ha forjado la diferencia básica entre, por un lado, los contendientes que tienen a su disposición los más sofisticados y eficientes medios de combate y, por otro, quienes no tienen siquiera posibilidad de acceso a éstos, rompiendo de este modo el principio básico de igualdad de armas entre los contendientes e imponiendo la distinción, en un escenario global que no conoce de fronteras estatales, entre los denominados Estados "high-tech" y "low-tech", respectivamente.

Se configura así el segundo de los aspectos que contribuye a dotar de especiales características a los conflictos armados internacionales más recientes hasta convertirlos en exponentes tanto de las llamadas "guerras de tercera generación" como de las "guerras de coste cero", en las que el contendiente mejor preparado tecnológicamente tiene capacidad para elegir los medios a través de los cuales causar graves daños al enemigo sin que quepa prever una respuesta por parte de éste que le cause gran número de bajas, esto es, "cero bajas" para el contendiente técnicamente más adelantado.

No obstante, el examen de la práctica internacional muestra que en ocasiones los Estados "high-tech" no han podido doblegar a un beligerante tecnológicamente inferior en el marco de las denominadas "guerras de cuarta generación" o "guerras asimétricas", donde los ejércitos dotados de altas tecnologías se enfrentan a fuerzas irregulares y actores no estatales que disponen de medios de combate muy inferiores. 
Se pondría así de manifiesto uno de los rasgos característicos de este tipo de conflictos, en los que una de las partes es consciente de su superioridad tecnológico-militar respecto de la otra y, en sentido contrario, de la situación de inferioridad de esta última, con el indeseable resultado de que ambas llegan al convencimiento de que no es necesario cumplir las normas del Derecho Internacional Humanitario.

Sobre el particular, hemos tenido ocasión de señalar que la confluencia de los avances tecnológicos y de la multiplicación de actores internacionales no estatales que emplean los medios y métodos de combate que las altas tecnologías ponen a su alcance, ha llegado a poner en cuestión la idoneidad de este sector del ordenamiento internacional para regular unos conflictos armados más complejos y desiguales que algún sector doctrinal denomina "híbridos".

Asimismo, se ha podido señalar en el presente trabajo los retos que exige la adecuación del Derecho Internacional Humanitario a las características específicas, tanto de estas nuevas modalidades de conflictos armados, como de las altas tecnologías que han convertido el ciberespacio en un nuevo escenario de conflicto en el que se suceden los ciberataques.

Un nuevo escenario donde las capacidades militares cibernéticas adquieren relevancia en términos ofensivos y defensivos y la evolución de internet y su presencia intrusiva en la vida cotidiana de prácticamente cualquier ser humano sobre el planeta constituyen un medio de combate especialmente idóneo para el contendiente técnicamente menos avanzado debido a su fácil acceso, escasa o nula regulación, anonimato, bajo coste económico, rapidez y efectividad.

De igual manera, consideramos que los avances tecnológicos más recientes han permitido dotar a los sistemas de armas de mayor autonomía en sus funciones críticas, lo cual plantea un desafío tecnológico con implicaciones jurídicas y humanitarias, en la medida en que resulta cuestionable su adecuación a los principios de distinción, proporcionalidad y precaución en el ataque que el Derecho Internacional Humanitario impone a los beligerantes.

En la misma línea cabría destacar cómo la progresiva robotización de las fuerzas armadas ocupa un papel cada vez más destacado en la actualidad gracias a la utilización de vehículos aéreos no tripulados, más conocidos popularmente como drones. El desarrollo vertiginoso de estas plataformas aéreas, que les permite ser empleadas no sólo para labores de vigilancia y obtención de información sino también como medios efectivos de combate, las ha convertido en un elemento estratégico clave, dada la naturaleza asimétrica de la mayor parte de los conflictos contemporáneos.

Al respecto, consideramos que si bien los avances tecnológicos y las capacidades técnicas de los drones en la actualidad no los convierte per se en un medio de combate contrario a las normas del Derecho Internacional Humanitario, tal y como ocurre con cualquier otro medio de combate, la 
conformidad de su utilización con dichas normas sólo puede afirmarse tras el análisis de cada una de las situaciones de conflicto y a la vista de los elementos que concurran en un caso concreto.

No resulta adecuado, por consiguiente, realizar afirmaciones genéricas acerca de la legalidad o no del empleo de vehículos aéreos no tripulados en el marco de un conflicto armado, aunque sí entendemos necesario sostener que su empleo para llevar a cabo los denominados "ataques selectivos" difícilmente puede ser considerado conforme con el Derecho Internacional Humanitario $\mathrm{y}$, en particular, con las obligaciones que impone a todos los beligerantes las normas consuetudinarias que recoge el artículo 3 común a las Convenciones de Ginebra de 1949. 


\section{Referencias bibliográficas:}

Adams, J., The Next World War: Warrior and Weapons of the New Battlefields of Cyberspace, Londres, Hutchinson, 1998.

Arnett, R.B., Asymmetrical Warfare: Today's Challenge to US Military Power, Virginia, Potomac Books Inc, 2003.

Aznar Fernández-Montesinos, F. y González Martí, A., Las generaciones de guerra. Guerras de segunda y tercera generación (II), "Boletín Electrónico del Instituto Español de Estudios Estratégicos”, Documento de Análisis 59/2015.

Baqués Quesada, J., Las guerras híbridas: un balance provisional, "Boletín Electrónico del Instituto Español de Estudios Estratégicos”, Documento de Trabajo 1/2015.

Barnhart, R.K.; Hottman, S.B.; Marshall, D.M. y Shappee, E. (eds), Introduction to Unmanned Aircraft Systems, Boca Raton, CRC Press, 2012.

Baud, J., La Guerre asymétrique ou la défaite du vainqueur, Paris, Editions du Rocher, 2003.

Bellflower, J.W., 4th Generation Warfare, "Small Wars Journal" , 4 (2006

Blank, L.R., After “Top Gun”: How Drone Strikes Impact the Law of War, "University of Pennsylvania Journal of International Law", 33 (2012).

Blom, J.D., UAS: A Historical Perspective, "Combat Studies Institute Press", Kansas, (2010).

Bhuta, N., States of Exception: Regulating Targeted Killing in a "Global Civil War”, en Philip Alston y Euan Mc Donald, eds.: Human Rights, Intervention and the Use of Force, Oxford, Oxford University Press, 2008.

Clarke, R.A. y Knake, R.K., Guerra en la red. Los nuevos campos de batalla, Barcelona, Ariel, 2011.

Colom, G., Entre Ares y Atenea: el debate sobre la Revolución en los Asuntos Militares, Madrid, Instituto Universitario General Gutiérrez Mellado, 2008.

- Cambio y continuidad en el pensamiento estratégico estadounidense desde el final de la Guerra Fría, "Revista de Ciencia Política", 33 (2013).

- ¿El auge de los conflictos híbridos?, "Boletín Electrónico del Instituto Español de Estudios Estratégicos”, Documento de Opinión 120/2014.

Courmont, B., y Ribnikar, D., Les guerres asymétriques, Paris, Presse Universitaire de France, 2002.

David, Ch-Ph., La guerra y la paz, Barcelona, Icaria, 2008.

Dyer, J.W., Robots make war more survivable, "Armed Forces Journal” (2007).

Fatjó, P. y Colom, G., La guerra asimétrica: Olvidando la historia, en Carlos Cueto, coord.: Los desafios de las Fuerzas Armadas en el siglo XXI, Granada, Comares, 2008. 
Fleming, B. The Hybrid threat concept: Contemporary war, military planning and the advent of unrestricted operational art, Fort Leavenworth, U.S. Army Command and General Staff College, 2011.

García Rico, E.M., El Derecho Internacional Humanitario ante la doctrina de las "zero casualties warfare, en Víctor Gutiérrez Castillo y Alfredo Langa Herrero, coords.: Los conflictos armados en la era de la globalización, Sevilla, 2007.

- Problemas y desafíos que los conflictos asimétricos plantean en el contexto del ius in bello, en Amérigo Cuervo-Arango, F. y Peñaranda Algar, J., coords.: Dos Décadas de Posguerra Fría. Actas de las I Jornadas de Estudios de Seguridad de la Comunidad de Estudios de Seguridad "General Gutiérrez Mellado", Madrid, 2009.

- Los conflictos armados del siglo XXI: ¿nuevos conflictos viejas normas?,en José Martín y Pérez de Nanclares, coord., Estados y Organizaciones Internacionales ante las nuevas crisis globales, Madrid, 2010.

Glenn, R., Thoughts on Hybrid Conflict, "Small Wars Journal", 13 (2009).

Gómez Isa, F., Los ataques armados con drones en Derecho Internacional, "Revista Española de Derecho Internacional", 67 (2015).

Grasa, R., Cincuenta años de evolución de la investigación para la paz, Barcelona, Colección Recerca per la Pau. Oficina de Promoció de la Pau i dels Drets Humans. Generalidad de Cataluña, 2010. pg. 73

Hammes, T.X., War Evolves into the Fourth Generation, "Contemporary Security Policy", 26 (2005).

Hoffman, F., Complex-irregular warfare: The next Revolution in Military Affairs, "Orbis", 50 (2006).

- Conflict in the 21st Century: The rise of hybrid wars, Arlington, Potomac Institute for Policy Studies, 2007.

- Future Hybrid Threats: An Update, Center for Strategic Research, Institute for National Strategic Studies, Washington DC, 2012.

Jaime-Jiménez, O., Riesgos y respuestas desde la seguridad de un mundo “glocalizado", Madrid, Biblioteca Nueva, 2004.

Jordán, J. y Baqués, J., Guerra de Drones. Política, tecnología y cambio social en los nuevos conflictos, Madrid, Biblioteca Nueva, 2014.

Lejarza Illaro, E., Ciberguerra, los escenarios de confrontación, "Boletín Electrónico del Instituto español de Estudios Estratégicos”, Documento de Opinión 18/2014.

Liff, A.P., Cyberwar: A New 'Absolute Weapon'? The Proliferation of Cyberwarfare Capabilities and Interestate War, "The Journal of Strategic Studies", 35 (2012).

Lin, P.; Bekey, G.; Abney, K., Autonomous Military Robotics: Risk, Ethics, and Design, San Luis Obispo, California Polytechnic State University, 2008. 
Lind,W.S., Understanding Fourth Generation War, "Military Review", (2004). Lind, W.S. y Thiele, G.A., 4th Generation Warfare Handbook, Finlandia, Castalia House, 2015.

Llandrés Cuesta, B., Los UAS, una valoración sobre su uso, "Boletín Electrónico del Instituto español de Estudios Estratégicos", Documento de Opinión $134 / 2015$.

Lynn, W. J., Defending a New Domain, "Foreign Affairs", 80 (2010).

Mattis. J. y Hoffman, F., Future warfare: The rise of hybrid warfare, "U.S. Naval Institute Proceedings", 132 (2005).

Metz, S., La guerre asymétrique et l'avenir de l'Occident, «Politique Étrangére», (2003).

Miller W.L. y Langdom M., Fourth generation R\&D: Managing knowledge, technology, and innovation. John Wiley \& Sons, 2008.

Murray, W. y Mansoor, P., Hybrid Warfare, Fighting Complex Opponents from the Ancient World to the Present, Nueva York, Cambridge University Press, 2012.

Pozo, P., La utilización de los drones en los conflictos actuales: una perspectiva del derecho internacional, "Boletín Electrónico del Instituto Español de Estudios Estratégicos", Documento de opinión 37/2011.

Raboin, B., Corresponding Evolution: International Law and the Emergence of Cyber Warfare, "Journal of the National association of Administrative Law Judiciary", 31 (2011).

Robles Carrillo, M., La integración de la perspectiva de género en el análisis de los conflictos armados y la seguridad, "Cuadernos de Estrategia", 157 (2012), p. 66.

-El ciberespacio y la ciberseguridad: consideraciones sobre la necesidad de un modelo jurídico, "Boletín Electrónico del Instituto Español de Estudios Estratégicos", Documento de Opinión 124/2015.

Rogers, Anthony P.V., Zero-casualty warfare, "International Review of the Red Cross", 82 (2000).

Rogers, P., Political Violence and Asymmetric Warfare, Washington, Brookings Institution, 2001.

Sánchez, F., El conflicto híbrido, ¿una nueva forma de guerra?, en El enfoque multidisciplinar a los conflictos híbridos, Madrid, CESEDEN, 2012.

Sánchez Herráez, P., Guerras de cuarta generación. La solución: ¿tecnología?, "Revista Ejército", 282 (2008).

- La nueva guerra híbrida: un somero análisis estratégico, "Boletín Electrónico del Instituto español de Estudios Estratégicos”, Documento de análisis $54 / 2014$.

Schroefl. J. y Kaufman, S., Hybrid Actors, Tactical Variety: Rethinking Asymmetric and Hybrid War, "Studies in Conflict \& Terrorism", 37 (2014). 
Schmitt, M.N., The Principle of Discrimination in 21st Century Warfare, "Yale Human Rights and Development Law Journal", 143 (1999).

Shackelford, S.J., From Nuclear War to Net War: Analogizing Cyber Attacks in International Law, "Berkeley Journal of International Law", 25 (2009).

Singer P.W., Wired for War: Robotics Revolution and Conflict in the 21th Century, Nueva York, Penguin Press, 2009

Smith, Th.W., The New Law of War: Legitimizing Hi-Tech and Infrastructural Violence, "International Studies Quarterly", 46 (2002),

Sterio, M., The United States' Use of Drones in the War on Terror: The (I) legality of Targeted Killings Under International Law", "Case Western Reserve Journal of International Law", 45 (2012).

Strawser, B., Moral Predators: The Duty to Employ Uninhabited Aerial Vehicles, "Journal of Military Ethics", 9 (2010).

Toffler, A. y H., Las guerras del futuro, Barcelona, Plaza \&Janés, 1994.

Torres, M., Los dilemas estratégicos de la ciber-guerra, "Revista Ejército", 2011

Yenne, B., Attack of the Drones. A History of Unmanned Aerial Combat, St. Paul, Zennith Press, 2004.

Zelik, R., La Guerra Asimétrica. Una lectura crítica de la transformación de las doctrinas militares occidentales, "Estudios Políticos", 39 (2011). 
